\title{
THE
}

\section{Upper Mantle Structure of the Cascades from Full-Wave Ambient Noise Tomography: Evidence for 3D Mantle Upwelling in the Back- Arc}

Haiying Gao

Yang Shen

University of Rhode Island, y.shen@icloud.com

Follow this and additional works at: https://digitalcommons.uri.edu/gsofacpubs

The University of Rhode Island Faculty have made this article openly available.

Please let us know how Open Access to this research benefits you.

This is a pre-publication author manuscript of the final, published article.

Terms of Use

This article is made available under the terms and conditions applicable towards Open Access

Policy Articles, as set forth in our Terms of Use.

\section{Citation/Publisher Attribution}

Gao, H. \& Shen, Y. (2014). Upper mantle structure of the Cascades from full-wave ambient noise tomography: Evidence for 3D mantle upwelling in the back-arc. Earth and Planetary Science Letters, 390(15), 222-233. http://dx.doi.org/10.1016/j.epsl.2014.01.012

Available at: http://dx.doi.org/10.1016/j.epsl.2014.01.012

This Article is brought to you for free and open access by the Graduate School of Oceanography at DigitalCommons@URI. It has been accepted for inclusion in Graduate School of Oceanography Faculty Publications by an authorized administrator of DigitalCommons@URI. For more information, please contact digitalcommons-group@uri.edu. 
1 Upper mantle structure of the Cascades from full-wave ambient noise tomography:

2 Evidence for 3D mantle upwelling in the back-arc

3

4 Haiying Gao ${ }^{\mathrm{a}, \mathrm{b}, *}$, Yang Shen ${ }^{\mathrm{a}}$

5

6 a Graduate School of Oceanography, University of Rhode Island, Narragansett, RI 02882,

7 USA

$8{ }^{b}$ now at Department of Geosciences, 250 Morrill Science Center, University of

9 Massachusetts Amherst, MA 01003, USA, email: haiyinggao@geo.umass.edu, phone:

$10 \quad 413-577-1250$

13 ABSTRACT

14 Melt generation and volcanism at subduction zones may result from several possible

15 processes: hydration of the mantle wedge by fluid released from the slab, subduction16 induced mantle upwelling beneath the back-arc, and heating of downgoing 17 sediments/oceanic crust atop the slab. Each process predicts a distinctly different spatial

18 pattern of melt generation and can thus be distinguished with high-resolution seismic

19 imaging. Here we construct an upper mantle model of the Pacific Northwest using a full-

20 wave ambient noise tomographic method. Normalized vertical components of continuous

21 seismic records at station pairs are cross-correlated to extract empirical Green's functions

22 at periods of 7-200 s. We simulate wave propagation within the 3D Earth structure using

23 a finite-difference method and calculate sensitivity kernels of Rayleigh waves to 
24 perturbations of Vp and Vs based on the Strain Green's Tensor database. Phase delays

25 are extracted by cross-correlating the observed and synthetic waveforms at multiple

26 frequency bands.

27 Our tomographic result reveals three separate low shear-wave velocity anomalies

28 along the back-arc in the upper mantle $\sim 200 \mathrm{~km}$ east of the Cascade volcanic arc, with the

29 central one being the largest in size and lowest in velocity. These back-arc low-velocity

30 anomalies are spatially correlated with the three arc-volcano clusters. The geometry of

31 the low-velocity volumes relative to the slab and arc is consistent with the pattern of

32 subduction-induced decompressional melting in the back-arc. Their along-strike variation

33 suggests that the large-scale plate-motion-induced flow in the back-arc mantle wedge is

34 modulated by small-scale convection, resulting in a highly 3D process that defines the

35 segmentation of volcanism along the Cascade arc.

37 Keywords: full-wave ambient noise tomography, the Cascadia subduction zone, low38 velocity anomaly, decompressional melting

41 1. Introduction

42 The mechanisms of melt generation in the upper mantle wedge (Figure 1) have been 43 the focus of numerous studies, as they are fundamental to our understanding of arc 44 volcanism along subduction zones. In general, melt production is positively correlated to 45 water content in arc basalt (Kelley et al., 2006), which supports flux melting by fluid 46 released from the subducting slab (van Keken, 2003). Subduction-induced mantle 
47 upwelling and decompressional melting explains existence of nearly anhydrous lavas, as

48 well as low seismic velocities and high attenuation at the back-arc spreading center

49 (Conder et al., 2002; Wiens et al., 2008). Melting of the oceanic crust/sedimentary layer

50 atop the slab also contributes significantly to the trace element signatures at arc volcanoes

51 and the thermal structure of the mantle wedge (Conder, 2005). The melting processes and

52 their relative importance at various subduction zones may depend on the slab age,

53 sediment thickness, subduction rate, and other factors.

54 Melt generation also varies along strike. At the Honshu subduction zone, northeast

55 Japan, body-wave tomography reveals strong spatial correlation between the along-strike

56 segments of arc volcanoes and the low-velocity anomalies at the back-arc in the upper

57 mantle (named as 'hot fingers' by Tamura et al. (2002)). Numerical experiments with a

58 low-viscosity mantle wedge, presumably due to water released from the slab by

59 dehydration reaction, produce the finger-like small-scale convection (Honda and Yoshida,

60 2005). To our knowledge, the Honshu subduction zone is the only place where this

61 distinctive hot-finger structure has been imaged and correlated with arc volcanism. Are

62 the hot-finger structure and, by inference, small-scale mantle convection a general

63 phenomenon at subduction zones or unique to those with a possibly hydrated mantle

64 wedge in the back-arc produced by an old and cold slab subducting at a fast rate, such as

65 the western Pacific plate?

66 With a relatively young and thin slab and presumably shallow dehydration (van

67 Keken et al., 2011), the subduction of the Juan de Fuca plate beneath western North

68 America represents an end member in the subduction zone system. Along strike, the

69 subducting slab, the overriding plate and seismicity show clearly segmented signatures 
70 (Tréhu et al., 1994; Brocher et al., 2003; Burdick et al., 2008). In particular, the

71 Quaternary volcanoes are spatially clustered and different in the composition of primitive

72 basalts (Figure 2, Schmidt et al., 2008). The arc basalts show evidence for both flux and

73 dry melting, with the maximum water content lower than those found at other arcs

74 (Elkins Tanton et al., 2001; Ruscitto et al., 2010). Unlike the subduction zones with well-

75 developed back-arc spreading centers (e.g., Wiens et al., 2008), the Cascades have only

76 volumetrically minor and sparse Quaternary volcanic activities behind the arc (Till et al.,

77 2013). So the extent and form of subduction-induced mantle flow and decompressional

78 melting in the back-arc of the Cascades and those of similar continental subduction zones

79 remain enigmatic.

80 A well-defined crust and upper mantle velocity model is needed to understand the

81 melting processes and the causes of along-strike segmentation of volcanism in the

82 Cascadia subduction zone. Although there have been many velocity models for the

83 Cascades (Lee and Crosson, 1990; Symons and Crosson, 1997; Parsons et al., 1999; Zhao

84 et al., 2001; Brocher et al., 2001; Calvert et al., 2001; Shapiro and Ritzwoller, 2002;

85 Tréhu et al., 2002; van Wagoner et al., 2002; Crosson et al., 2002; Graindorge et al.,

86 2003; Ramachandran et al., 2004; Burdick et al., 2008, 2010; Roth et al., 2008; Yang et

87 al., 2008; Abers et al., 2009; Audet et al., 2009; Moschetti et al., 2010; Schmandt and

88 Humphreys, 2010; Calkins et al., 2011; Gao et al., 2011; Delorey and Vidale, 2011;

89 Porritt et al., 2011; Wagner et al., 2012; Shen et al., 2013), none of these models covers

90 the entire subduction zone, has high enough resolution at the depth of melt generation,

91 and is adequately accurate to explain the observed waveforms as illustrated by Gao and

92 Shen (2012) with full-wave simulation. In addition, the magnitudes of velocity 
93 perturbations in the existing models resolved from body-wave tomography in the Pacific

94 Northwest (Roth et al., 2008; Burdick et al., 2008, 2010; Obrebski et al., 2010, 2011;

95 Schmandt and Humphreys, 2010, 2011; James et al., 2011; Sigloch, 2011) vary within a

96 wide range (Becker, 2012). Furthermore, the resolution gap in the upper mantle between

97 surface-wave tomography and body-wave tomography limits geodynamic interpretations

98 at the depth of melt generation.

99 In this study, we invert for the upper mantle structure of the Pacific Northwest using

100 an advanced full-wave tomographic method based on simulation of wave propagation

101 within the 3D Earth structure (Zhang et al., 2012). Compared to previous studies, three

102 factors significantly improve the model resolution: First, there has been a huge increase

103 in broadband seismic data in the Pacific Northwest. We have processed ambient noise

104 waveforms from $\sim 1000$ stations (see station distribution in Figure 2); Secondly, we have

105 developed a new waveform normalization method (Shen et al., 2012) that improves the

106 quality of surface waves extracted from ambient seismic noise and are able to obtain

107 much more broadband and higher quality Rayleigh waves than in previous studies

108 (Figure 3); and thirdly, the full-wave tomographic method is based on wave propagation

109 simulation in 3D models, a more accurate theory that relates seismic data to the Earth

110 structure (Zhao et al., 2005; Chen et al., 2007; Shen and Zhang, 2010). Unlike previous

111 studies of the Pacific Northwest, we calculate the sensitivities of Rayleigh waves to

112 perturbations of both $\mathrm{Vp}$ and Vs and jointly invert for the velocity model. The velocity

113 model is then improved by iteratively reducing the misfit between the observed and

114 synthetic waveforms.

115 
117 The procedure of the full-wave ambient noise tomography includes extraction of

118 empirical Green's functions (EGFs) from continuous ambient noise waveform, finite-

119 difference wave propagation simulation in the 3D Earth structure, measurement of phase

120 delays between observed and synthetic waveforms, calculation of sensitivity kernels and

121 inversion for velocity perturbations. The first three steps are fully described by Gao and

122 Shen (2012), so we only briefly summarize here.

124 2.1. Extraction of empirical Green's functions

125 To retrieve Rayleigh-wave EGFs between station pairs, we process the vertical 126 component of continuous seismic data recorded between 1995 and 2012 by about 1000

127 stations in an area extending from northern California to Vancouver Island, Canada

128 (Figure 2). We include seismic stations from the EarthScope USArray Transportable 129 Array (TA), the Canadian National Seismograph Network (CN), the Plate Boundary 130 Observatory borehole seismic network (PB), the Portable Observatories for Lithospheric 131 Analysis and Research Investigating Seismicity (PO), the University of Oregon regional 132 network (UO), the Pacific Northwest regional seismic network (UW), the United States 133 national seismic network (US), the Berkeley digital seismography network (BK), the 134 Cascade chain volcano monitoring (CC), the Caltech regional seismic network (CI), and 135 many other flexible arrays including High Lava Plains broadband seismic experiment 136 (XC), Mendocino experiment (XQ), Cascadia arrays for EarthScope (XU), Flexarray 137 along Cascadia experiment for segmentations (YW), and Wallowa broadband experiment 138 (ZG). To our knowledge, this is the first time that all these networks are combined for 
139 surface-wave tomography, resulting in a dataset that provides the most comprehensive, 140 dense coverage of the study area.

141 Prior to cross-correlating the vertical-component waveforms from station pairs, we 142 remove instrument response, normalize ambient noise data with a frequency-time143 normalization method (Shen et al., 2012), and eliminate time segments of large (M>5.5)

144 earthquakes. To increase the signal-to-noise ratio, we stack daily cross-correlations for 145 each station pair, producing high-quality Rayleigh waves at periods of 7-200 s (Figure 3).

146 As this study focuses on structures from the mid-crust to upper mantle, for computational 147 reasons we only use $15-200$ s periods in the analysis described here. The EGFs are then 148 recovered as the time derivative of the stacked cross-correlations (e.g., Sabra et al., 2005;

149 Snieder, 2004). In addition, we obtain monthly stacks of cross-correlations, whose 150 variations provide estimates of the uncertainties of EGFs and their travel times.

151 The conditions to equate EGFs with Green's functions of the Earth include a uniform 152 distribution of noise sources around the seismic stations and zero attenuation (e.g., 153 Wapenaar, 2004; Wapenaar and Fokkema, 2006). These conditions are usually not 154 strictly satisfied in ambient noise seismic tomography (e.g., Yang and Ritzwoller, 2008) 155 and the Pacific Northwest is no exception as most of the ambient noise comes from the

156 Pacific Ocean. Following helioseismological practices in dealing with similar issues, 157 Tromp et al. (2010) suggested construction of ensemble-averaged cross-correlation and 158 corresponding ensemble-averaged sensitivity kernels. This method requires the power 159 spectral distribution of the ambient noise sources, which is highly variable spatially and 160 temporally (e.g., Uchiyama and McWilliams, 2008; Bromirski and Gerstoft, 2009). To 161 construct ensemble cross-correlations, we must know the global power spectral 
162 distribution of ambient noise sources for the various overlapping recording periods of

163 station pairs. This detailed knowledge of the global power spectral distribution of

164 ambient noise sources is currently unavailable and requires substantial work that is

165 beyond the scope of this study. On the other hand, it has been suggested that the non-

166 uniformity of noise sources would significantly affect the surface-wave amplitude (Tsai

167 and Moschetti, 2010) but not the velocity (Snieder, 2004). Numerical experiments show

168 that the non-uniform distribution of noise sources leads to less than $0.5 \%$ error in travel

169 times and phase velocity (Yang and Ritzwoller, 2008). This level of error is much less

170 than the lateral velocity variations in the Cascades (e.g., Porritt et al., 2011; Gao et al.,

171 2012). Furthermore, for the study area with an average travel time of $\sim 150 \mathrm{~s}$, a $0.5 \%$ error

172 is equivalent to a $\sim 0.75$-s error in travel time, less than measurement errors and the RMS

173 data misfit. In the following, we consider the effects of non-uniform noise source

174 distribution on travel times secondary to those of the Earth structure, and EGF a close

175 approximation to the Green's function of the Earth for velocity inversion.

177 2.2. Finite-difference wave simulation

178 We implement a nonstaggered-grid, finite-difference method to simulate wave 179 propagation in the 3D spherical Earth structure (Zhang et al., 2012). Each seismic station

180 is considered as a virtual source and all others as receivers. The regional 3D shear-wave

181 velocity model by Gao et al. (2011) is chosen as the initial reference model, merged with

182 CUB (Shapiro and Ritzwoller, 2002) at locations beyond the coverage of the original

183 model. Deeper than $400 \mathrm{~km}$, we use the AK135 model (Kennett et al., 1995). P-wave

184 velocity is converted from shear-wave velocity with a $\mathrm{Vp} / \mathrm{Vs}$ ratio of 1.74 in the crust 
185 (Brocher, 2005) and the depth-dependent relationship of Vp and Vs of AK135 in the

186 mantle (Kennett et al., 1995). Density is calculated as a function of Vp (Christensen and

187 Mooney, 1995). Constraints on the Moho depth (Lowry and Pérez-Gussinyé, 2011) are

188 added to the initial reference model. No anisotropy and attenuation are included in the

189 simulation, though the effect of attenuation is considered in the interpretation of the

190 tomographic results.

191 For computational reasons, we carry out two levels of finite-difference wave

192 simulation, starting from a coarser grid for longer-period waves. The horizontal grid

193 spacing is $10 \mathrm{~km}$ and $5 \mathrm{~km}$ for level 1 and level 2, respectively, along the geographic

194 longitude and latitude. The vertical grid spacing is about one-third of the horizontal

195 spacing near the surface and increases with depth to approximately the same as the

196 horizontal spacing at $\sim 100 \mathrm{~km}$ depth. Such grid sizes are sufficient to accurately simulate

197 waves at periods greater than $40 \mathrm{~s}$ and $21 \mathrm{~s}$ for level 1 and level 2, respectively (Zhang et

198 al., 2012). The total wave propagation time is $1000 \mathrm{~s}$ as the longest inter-station distance

199 is $\sim 3000 \mathrm{~km}$. To maintain numerical stability, we use a time step of $0.5 \mathrm{~s}$ for level 1 and

$200 \quad 0.25 \mathrm{~s}$ for level 2. To calculate Green's functions, we use a Gaussian pulse with a half

201 width of $7.5 \mathrm{~s}$ and $4 \mathrm{~s}$, respectively, as the source-time function of the vertical force

202 applied at the virtual station. The wave simulations are executed on a Linux cluster with

20317 nodes (each with 24 cpu-cores). It takes about 0.3 and 1 hour per simulation with two

204 nodes for level 1 and level 2, respectively.

205

206 2.3. Cross-correlation of EGFs and synthetics 
207 The phase delay times between the EGFs and synthetics are measured by cross208 correlation at multiple overlapping period bands, with the central periods of $55 \mathrm{~s}, 75 \mathrm{~s}$, $209112.5 \mathrm{~s}, 150 \mathrm{~s}$, and $200 \mathrm{~s}$ for level 1 and $22.5 \mathrm{~s}, 37.5 \mathrm{~s}, 56 \mathrm{~s}, 75 \mathrm{~s}$, and $112.5 \mathrm{~s}$ for level 2.

210 The corresponding Rayleigh waves have peak sensitivities to structures from the mid-

211 crust to $250 \mathrm{~km}$ depth. In this paper, we focus our interpretations on the mantle structure

$212(50-140 \mathrm{~km})$. Before the delay measurement, the EGFs are convolved with the source-

213 time function used in the calculation of Green's functions to account for the finite-

214 frequency nature and initial time shift of the simulated Green's functions. To ensure high215 quality signals, the signal-to-noise ratio of EGFs is required to be at least eight, the inter-

216 station distance at least 1.5-wavelength, and the cross-correlation coefficient between the

217 EGFs and synthetics greater than 0.90 . The number of measured phase delays varies from $218 \sim 3,000$ to 20,000 within different frequency bands.

220 2.4. Sensitivity kernels and inversion method

221 In previous surface-wave tomographic studies (e.g., Yang et al., 2008; Gao et al., 222 2011; Porritt et al., 2011; Wagner et al., 2012), the inversion of phase velocity to shear-

223 wave velocity is carried out under the assumption that Rayleigh waves are not affected by

224 P-wave speed. This is not accurate, especially at shallow depths (Figure S1). We 225 represent the Rayleigh wave phase delay time $\delta \mathbf{t}$ as a joint Vp and Vs inverse problem,

$$
\delta \mathbf{t}=\int\left[K_{\alpha}\left(\mathbf{m}_{0}, x\right) \Delta \mathbf{m}_{\alpha}+K_{\beta}\left(\mathbf{m}_{0}, x\right) \Delta \mathbf{m}_{\beta}\right] d V
$$

227 where $\mathbf{m}_{0}, \Delta \mathbf{m}_{\alpha}$ and $\Delta \mathbf{m}_{\beta}$ are the 3D reference model, Vp and Vs perturbations, and $K_{\alpha}$ 228 and $K_{\beta}$ the Rayleigh-wave sensitivity kernels to $\mathrm{Vp}$ and $\mathrm{Vs}$, respectively. The integration 229 is for the 3D volume of the model. Although the velocity structure in the shallow crust is 
230 not well constrained in this study due to the intermediate- to long-period data used, the

231 inclusion of $\mathrm{Vp}$ in inversion provides additional degrees of freedom that minimize the

232 extent to which $\mathrm{Vp}$ anomalies in the shallow crust are mapped into the deep crust and

233 upper mantle. The effect of density is not explicitly expressed in the equation, but density

234 is recalculated based on Vp (Christensen and Mooney, 1995) after each iterative model

235 update. The sensitivity kernels are calculated with the strain-Green-tensor-based,

236 scattering-integral method (Zhao et al., 2005; Chen et al., 2007; Zhang et al., 2007). The

237 inverse problem is solved with damping and smoothness constraints. The best-fit

238 damping and smoothing parameters, which are gradually reduced with iterative

239 inversions, are chosen from the tradeoff of the normalized chi-squared value and the

240 model variance (Gao and Shen, 2012).

241 We start wave propagation simulation from level 1 to construct a large-scale

242 framework, which provides the reference model for level 2 . The model is then iteratively

243 updated by alternating the two-level full-wave tomographic imaging. The solution does

244 not change significantly after 3-4 iterations. In total, we run five iterations for each level.

245 Compared to the initial reference model, the updated model yields synthetic waveforms

246 that match the observed EGFs much better (Figure 4), with the standard deviation of

247 phase delays decreasing from $2.5 \mathrm{~s}$ to $0.7 \mathrm{~s}$. The phase delays of the updated model as a

248 function of inter-station distance are less scattered and centered around zero (Figure 5).

249 We observe that, on average, our model has much stronger velocity perturbations

250 compared to previous models (Shapiro and Ritzwoller, 2002; Yang et al., 2008; Gao et

251 al., 2011). It appears that more data and/or a more accurate methodology result in a

252 stronger contrast of the velocity anomalies. This has also been observed in the western 
253 U.S. among various body-wave tomographic studies (as compared by Becker (2012)),

254 Iceland (Hung et al., 2004), and the Lau Basin (Wiens et al., 2006, 2012).

256 3. Seismic Results and Discussion

257 We focus our discussion on the mantle structure, in the depth range that is best 258 constrained by the ambient noise data and most relevant to melt generation (40-140 $\mathrm{km})$.

259 Because the Rayleigh-wave sensitivity to Vp concentrates primarily in the shallow depth

260 (Figure S1), Vp in the mantle is not well constrained and thus not interpreted. Our shear-

261 wave velocity model, as shown in Figure 6, has features that are similar to those in the

262 previous tomographic models. For example, we image the low-velocity Yellowstone

263 hotspot at all the depths (e.g., Moschetti et al., 2010; Gao et al., 2011; Wagner et al.,

264 2012), an observation that is consistent with the active magmatism and high surface heat

265 flow (Lowry and Pérez-Gussinyé, 2011). The geometry of the subducting slab is better

266 resolved in this study at depths greater than $80 \mathrm{~km}$ than in previous surface-wave studies

267 (e.g., Yang et al., 2008; Gao et al., 2011; Porritt et al., 2011; Wagner et al., 2012). The

268 seismic velocity of the subducting slab is heterogeneous along strike. At depth of $\sim 110$

$269 \mathrm{~km}$, we image a slab hole (or weak slab) in northern Oregon, which spatially correlates

270 with a similar gap or weak slab in the body-wave tomographic models at depths greater

271 than 160 km (Roth et al., 2008; Burdick et al., 2008; Schmandt and Humphreys, 2010).

272 The most striking features of our Cascade model are three low shear-wave velocity 273 volumes, with velocities as low as $\sim 3.6 \mathrm{~km} / \mathrm{s}$, in the upper mantle along the back-arc

274 (Figures 6 and 7). The back-arc low-velocity anomalies are about $200 \mathrm{~km}$ away from the

275 arc, segmented along strike and correlate spatially with the three volcano clusters along 
276 the Cascades (Figure 2). The inter-spacing of these anomalies (center to center) is $\sim 300$

$277 \mathrm{~km}$. Large-scale, separate low-velocity anomalies have also been imaged in the upper

278 mantle wedge along the Izu-Bonin-Mariana arc (where the spacing of the anomalies is

$279 \sim 500 \mathrm{~km}$ ), and are interpreted as heterogeneous along-strike mantle flow (Isse et al.,

280 2009). Among the three anomalies, the central one at the Oregon back-arc is the largest in

281 size and lowest in velocity and corresponds to the arc segment with the largest

282 Quaternary eruption volume (Sherrod and Smith, 1990).

283 Analysis of model resolution in full-wave inversion is complicated by several factors,

284 including the non-linear relationship between the data and model and the multiple model

285 iterations carried out to reach the final model. The prohibitive cost of forward wave

286 propagation simulation makes the probabilistic approaches commonly used to deal with

287 nonlinear inverse problems impractical. Fichtner and Trampert (2011) proposed a method

288 based on the Fréchet derivatives of the misfit function. Their method, however, depends

289 on the condition that the model is in the vicinity of an optimal Earth model and the global

290 minimum of the misfit function has been found, an assumption that is difficult to verify in

291 large-scale, nonlinear full-wave inversion.

292 Synthetic inversion of various input models is a common practice in tomographic

293 resolution analysis. This approach has limitations and can be misleading in the sense that

294 synthetic inversion explores only a limited model subspace (Lévêque et al., 1993).

295 Nevertheless, it is useful if the limitations are understood and interpretations are

296 restricted to the model subspaces explored. With this caveat in mind, we run multiple

297 resolution tests. We first use our preferred model as the input (Figure 6). The synthetic

298 phase delay times are calculated with the sensitivity kernels (Eq. 1). The uncertainties of 
299 individual observed phase measurements are estimated from the variations of monthly-

300 stacked EGFs and added to the synthetic phase delays. The velocity perturbations of the

301 input model are well reconstructed in inversion at the depth of our interest (Figures 9 and

30210 ). We then run the $3 \mathrm{D}$ checkerboard resolution tests with a maximum of $\pm 10 \%$ velocity

303 perturbations for both Vp and Vs (Figures S2-S4). The velocity variation within each

304 checkerboard cell is a cosine function. The dimensions of the checkerboard cells vary

305 from 100-200 km along the geographic longitude and latitude, and from 90-150 km

306 vertically. For the small checkerboard, although the pattern of the velocity perturbation

307 can be fairly well reconstructed, the magnitude is underestimated. For the larger

308 checkerboards, both the pattern and smooth variation of the magnitude can be well

309 recovered. The sizes of our observed back-arc low-velocity volumes are comparable to

310 the largest checkerboard. In the above tests, the recovered structures are obtained in a

311 single model iteration. A fully non-linear inversion with multiple iterations, as for the

312 observed data in this study, will further minimize the residual, resulting in a sharper

313 reconstruction of the model. The results in Figures 9 and 10 can thus be considered

314 conservative. Taken together, Figures 9 and 10 and the checkerboard tests indicate that an

315 Earth model with a structure that resembles the inferred back-arc low-velocity anomalies

316 is well resolved.

317 The three distinct, segmented low-velocity volumes along the Cascade back-arc in the

318 upper mantle are resolved for the first time. We attribute the resolution to the dense data

319 coverage, an EGF dataset with a broad frequency band well suited for imaging the crust

320 and upper $200 \mathrm{~km}$ mantle, and an advanced full-wave tomographic method. This allows

321 us to gain new insight into the dynamic processes of the Cascadia mantle wedge. 
323 3.1. What controls the reduction of shear-wave velocity?

324 The seismic velocity can be affected by a few factors, including temperature, water

325 content and presence of partial melt. As shown in Figure 8, the shear-wave velocity of the

326 back-arc anomalies is $3.6-4.0 \mathrm{~km} / \mathrm{s}$ within the depths of $80-120 \mathrm{~km}$, which are deeper and

327 lower compared to where melting is inferred for the 0-4 Ma Pacific mantle (Nishimura

328 and Forsyth, 1989), the Lau back-arc basin (Wiens et al., 2006, 2008), and the Izu-Bonin-

329 Mariana arc (Isse et al., 2009). This strongly suggests presence of melt beneath the

330 Cascade back-arc, although temperature, water content, and grain size can also contribute

331 to the reduction of seismic velocity. The young, subducting Juan de Fuca plate leads to

332 shallow dehydration and less subduction-related water input into the back-arc mantle

333 wedge to affect seismic velocities. This inference is supported by the observation that the

334 primitive basalts erupted on the back-arc side of the Cascades are nominally dry (Ruscitto

335 et al., 2010). The back-arc lithosphere inferred from our model is relatively thin (Figure

336 7), consistent with the receiver function images of the lithosphere-asthenosphere

337 boundary (Kumar et al., 2012; Hopper et al., 2013) and the high surface heat flow

338 (Blackwell et al., 1990; Ingebritsen and Mariner, 2010). However, mantle temperature

339 alone cannot explain the observed back-arc low-velocity anomalies. Using the method of

340 Jackson and Faul (2010) for the geothermal profiles estimated from the Cascade heat

341 flow (based on Currie et al. (2004), Figure 8c), we find that the predicted shear-wave

342 velocities are all much higher than the observed (Figure 8b). The lowest velocity

343 calculated with the geotherms is $\sim 4.2 \mathrm{~km} / \mathrm{s}$ within the depth range of $80-110 \mathrm{~km}$, which is

344 more than $0.4 \mathrm{~km} / \mathrm{s}$ higher than the observed velocities beneath the back-arc low-velocity 
345 anomalies (blue lines in Figure 8b). Correction for attenuation ignored in forward wave

346 simulation assuming a low Q value of 50 (Dalton et al., 2008) reduces the velocity

347 mismatch by $\sim 0.1 \mathrm{~km} / \mathrm{s}$ to $0.3 \mathrm{~km} / \mathrm{s}$. The additional velocity reduction needed to match

348 the observed is indicative of the presence of partial melt, which can drastically reduce

349 shear-wave velocities. The electromagnetic study in the region (Egbert, 2012) also

350 supports the possible presence of melt in the back-arc.

351 Using S-to-P converted phases (Sp), Hopper et al. (2013) map the lithosphere-

352 asthenosphere boundary (LAB) beneath the Pacific Northwest. The depth of their LAB is

353 consistent with the base of the imaged high-velocity mantle lid of the upper plate (Figure

354 7), including the deepening of the LAB from the back-arc in south and central Oregon to

355 the back-arc of Washington, where the latest magmatism occurred more than $15 \mathrm{Ma}$ ago.

356 Hopper et al. (2013) attribute the consistent Sp observed beneath the Cascades back-arc

357 to the negative $\mathrm{LAB}$ velocity gradient created by a layer of partial melt ponding beneath a

358 solidus-defined boundary. Interestingly, strong Sp phases - in other words a large and/or

359 sharp negative velocity gradient at the LAB - are clustered in three areas in the back-arc

360 that roughly overlap with the three low-velocity volumes (Figure 7). A simple

361 explanation of the spatial overlap between the strong Sp phase and low-velocity volumes

362 is that the low-velocity volumes represent the regions of partial melt production. Melts

363 migrate upwards to collect at the base of the lithosphere, causing a relatively large and/or

364 sharp negative velocity gradient to generate the strong Sp phase.

365

366 3.2. What processes contribute to the pattern of the back-arc anomalies? 
The geometry and magnitude of the velocity anomalies in the mantle wedge and their 368 spatial correlation with the arc volcanoes provide constraints on the mechanism of melt 369 generation at the Cascades. Compositionally buoyant small-scale diapirs (Figure 1)

370 triggered by fluid released at the slab arise from the top of the slab with a more or less 371 vertical geometry beneath the arc (Hasenclever et al., 2011). These clearly do not match 372 the observed back-arc low-velocity volumes. Nevertheless, we cannot exclude the 373 possibilities of melting related to small-scale diapirs (Hall and Kincaid, 2001) because of

374 the difficulties in tomographically imaging such small-scale features. Beneath the Oregon 375 Cascade arc, where a hydrated uppermost mantle wedge has been suggested previously 376 (Bostock et al., 2002), the low-velocity zone atop and approximately parallel to the slab 377 extending from depth of $\sim 100 \mathrm{~km}$ upward to $\sim 60 \mathrm{~km}$ near the Cascade arc (Figure $7 \mathrm{c}$ ) is 378 consistent with flux melting (Wiens et al., 2008; Zhao et al., 1997). Note that the plate 379 interface terminates at depth of $100 \mathrm{~km}$ and is poorly defined at greater depths (McCrory 380 et al., 2004, 2012). The lack of such a low-velocity zone along the entire arc (Figures 7b, $3817 \mathrm{c}$ and $7 \mathrm{~d}$ ), however, indicates a variable strength of flux melting along the arc.

382 The pattern of the back-arc low-velocity anomalies (Figures $7 \mathrm{~b}, 7 \mathrm{c}$ and $7 \mathrm{~d}$ ) is most 383 consistent with subduction-induced mantle upwelling and decompressional melting 384 (Figure 1). The asthenospheric flow from beneath the old and thick North America 385 continental lithosphere towards the mantle wedge must undergo decompression. The fact 386 that the lowest velocities are at $80-110 \mathrm{~km}$ depth suggests that melting may involve damp 387 (50-200 p.p.m $\mathrm{H}_{2} \mathrm{O}$ ) peridotite and/or carbonated peridotite (Dasgupta et al., 2013). 388 Bifurcation of the Yellowstone plume driven by subduction-induced mantle flow 389 (Kincaid et al., 2013) may contribute to an excess mantle temperature and the stronger 
390 anomaly beneath the Oregon back-arc, though bifurcation of the plume cannot explain all

391 three back-arc low-velocity volumes. We suggest that the decompressional melts in the

392 back-arc are not only responsible for the volcanism in the back-arc (Till et al., 2013), but

393 also a likely source of the low-water-content magmas at the arc (Elkins Tanton et al.,

394 2001; Ruscitto et al., 2010) 200 km away. Melts may migrate upslope along a dipping

395 decompaction channel near the base of the lithosphere (Sparks and Parmentier, 1991),

396 though the exact mechanism of melt migration remains unclear.

397 Extension of the northern Basin and Range may contribute to the velocity reduction

398 in the southern Cascades (Ingebritsen and Mariner, 2010; Wang et al., 2002). However,

399 this mechanism cannot explain the back-arc low-velocity anomalies to the north.

400 Furthermore, the Basin and Range goes beyond the study area, while the southern low-

401 velocity anomaly extends only to near the southern end of the slab (Figure 2). The spatial

402 mismatch with the Basin and Range and the close correlation with the slab and the arc

403 volcanoes suggest that the low-velocity anomaly beneath the southern Cascade back-arc

404 reflects primarily the subduction processes.

405 Laboratory experiments with slab rollback and small back-arc extension that mimic

406 the Cascadia subduction zone indicate that upwelling above the slab in the mantle wedge

407 is influenced by the large-scale plate motion (Druken et al., 2011). The laboratory

408 experiments show the strongest upwelling in the center of the slab, which matches the

409 largest low-velocity anomaly in our seismic imaging. However, the magnitude of

410 upwelling varies gradually along strike from the center to the edge in the laboratory

411 experiments, different from the segmented pattern of our observed low-velocity

412 anomalies. Thus, besides the plate-motion-controlled processes other mechanisms must 
413 also be at work in Cascadia. One likely mechanism is small-scale convection due to

414 buoyancy associated with melting, differences in the temperature of the upwelling

415 mantle, negative buoyancy from the cooling of the lithosphere above, and pre-existing 416 lithosphere structure. Between the central and northern low-velocity volumes, the SKS-

417 splitting anisotropy pattern is complex and deviates from the plate motion direction

418 (Yuan and Romanowicz, 2010), possibly the consequence of the disturbance of lattice-

419 preferred orientation by small-scale convection in the mantle wedge (Morishige and

420 Honda, 2011).

421 The tight spatial correlation between the low-velocity volumes in the Cascade back-

422 arc and the volcano clusters is similar to the hot-finger structure at the Honshu subduction

423 zone (Tamura et al., 2002), which may be a consequence of small-scale convection

424 within a low-viscosity wedge in the Japan back-arc (Honda and Yoshida, 2005).

425 However, there is a notable difference between the Cascade back-arc anomalies and the 426 hot-finger structure beneath Honshu: The spacing of the volcano clusters and the finger427 like feature in Honshu is $50-100 \mathrm{~km}$, much smaller than at the Cascades. Numerical 428 simulations show that the formation and dimension of small-scale convection depend on 429 the slab age, subducting rate and water flux into the mantle released from the slab, which 430 affects mantle viscosity (Honda and Yoshida, 2005). Furthermore, long-wavelength rolls 431 dominate in the early development of small-scale convection and/or for cases with a 432 small subduction speed, while short-wavelength rolls take over in late stages and/or for 433 cases with a large subduction speed (Honda, 2011). Compared to Honshu, the Cascadia 434 subduction zone is younger (subduction started about $48 \mathrm{Ma}$ versus over $130 \mathrm{Ma}$ ) and has 435 a lower subduction speed $(3.5 \mathrm{~cm} / \mathrm{yr}$ versus $9 \mathrm{~cm} / \mathrm{yr})$. Thus, the link between the 
436 wavelength of small-scale 3D convection and clustering of arc volcanoes at different

437 subduction zones may reflect the different subduction histories and the relatively dry or

438 wet nature of the mantle wedge.

440 4. Conclusions

441 A new upper mantle shear-wave velocity model in the Pacific Northwest has been 442 constructed in this study using an advanced full-wave ambient noise tomographic

443 method. We have imaged three segmented low-velocity $(\sim 3.6-4.0 \mathrm{~km} / \mathrm{s})$ volumes along

444 the Cascade back-arc within the depth range of 80-115 km, which provides new insights

445 into the melting processes at the Cascadia subduction zone. Such low-velocity anomalies

446 require presence of partial melt within a hot upper mantle wedge. The correlation of the

447 three back-arc low-velocity anomalies in the mantle wedge with the volcanic arc and the 448 subducting slab is consistent with the pattern predicted by subduction-induced 449 decompressional melting. Furthermore, the along-strike variation suggests existence of 450 small-scale convection with a scale of $\sim 300 \mathrm{~km}$. Whether and how the melts generated

451 within the back-arc low-velocity volumes supply the low-water-content magmas at the

452 arc (Elkins Tanton et al., 2001; Ruscitto et al., 2010) remain unknown.

453 Whether small-scale mantle convection and 3D decompressional melting are 454 ubiquitous in the back-arc of subduction zones requires further understanding of the 455 connections between large-scale plate-driven processes and small-scale convection. 456 Although our shear-wave velocity model provides important constraints on the melting 457 processes in Cascadia, several other lines of work should be carried to further constrain 458 the complex 3D processes at the subduction zone. Our interpretation of the existence of 
459 back-arc decompressional melting is based mainly on the shear-wave velocity model.

460 Poisson's ratio is in fact more sensitive to melt and fluid than Vp and Vs. Attenuation

461 also reflects temperature, water content, and grain size. Therefore, a $\mathrm{Vp} / \mathrm{Vs}$ model and

462 attenuation structure (e.g., Lawrence and Prieto, 2011) will help distinguish the

463 contributions of melt, fluid, temperature and chemical composition, and understand the

464 melting generation processes (e.g., Wiens et al., 2008).

465

466

467 Acknowledgements

468 All the seismic waveforms used in this study are obtained from the IRIS Data

469 Management Center and the Canadian National Seismograph Network. We thank

470 Katherine Kelley, Mark Parmentier, Kelsey Druken and Chris Kincaid for helpful

471 discussions. We thank Ulrich Faul for providing the code to calculate shear-wave

472 velocities. This research is supported by the National Science Foundation (grant number

473 1144771) and Air Force Research Laboratory (grant number FA9453-10-C-0217). 474

475

476 References

477 Abers, G. A., L. S. MacKenzie, S. Rondenay, Z. Zhang, A. G. Wech, and K. C. Creager

478 (2009), Imaging the source region of Cascadia tremor and intermediate-depth

479 earthquakes, Geology, 37, 1119-1122. 
Audet, P., M. G. Bostock, N. I. Christensen, and S. M. Peacock (2009), Seismic evidence

481 for overpressured subducted oceanic crust and mega-thrust fault sealing, Nature, 457, $482 \quad 76-78$.

483 Becker, T. W. (2012), On recent seismic tomography for the western United States, 484 Geochem. Geophys. Geosyst., 13, Q01W10, doi:10.1029/2011GC003977.

485 Blackwell, D. D., J. L. Steele, M. K. Frohme, C. F. Murphey, G. R. Priest, and G. L. 486 Black (1990), Heat flow in the Oregon Cascade Range and its correlation with 487 regional gravity, Curie point depths, and geology, J. Geophys. Res., 95, 19,475$488 \quad 19,493$.

489 Bostock, M. G., R. D. Hyndman, S. Rondenay, and S. M. Peacock (2002), An inverted 490 continental Moho and serpentinization of the forearc mantle, Nature, 47, 536-538.

491 Brocher, T. M., (2005), Empirical relations between elastic wavespeeds and density in 492 the Earth's crust, Bull. Seism. Soc. Am., 95 (6), 2081-2092.

493 Brocher, T. M., T. Parsons, A. M. Trehu, C. M. Snelson, and M. A. Fisher (2003), 494 Seismic evidence for widespread serpentinized forearc upper mantle along the 495 Cascadia margin, Geology, 31, 267-270.

496 Brocher, T. M., T. Parsons, R. A. Blakely, N. I. Christensen, M. A. Fisher, R. E. Wells, 497 and the SHIPS Working Group (2001), Upper crustal structure in Puget Lowland, 498 Washington: Results from the 1998 Seismic Hazards Investigation in Puget Sound, J. 499 Geophys. Res., 106, 13,541-13,564.

500 Bromirski, P. D., and P. Gerstoft (2009), Dominant source regions of the Earth's "hum" 501 are coastal, Geophys. Res. Lett., 36, L13303, doi:10.1029/2009GL038903.

502 Burdick, S., C. Li, V. Martynov, T. Cox, J. Eakins, T. Mulder, L. Astiz, F. L. Vernon, G. 
503 L. Pavlis, and R. D. van der Hilst (2008), Upper mantle heterogeneity beneath North

504 America from travel time tomography with global and USArray Transportable Array 505 data, Seismol. Res. Lett., 79, 384-392.

506 Burdick, S., R. D. van der Hilst, F. L. Vernon, V. Martynov, T. Cox, J. Eakins, L. Astiz, 507 and G. L. Pavlis (2010), Model Update January 2010: Upper mantle heterogeneity

508 beneath North America from travel time tomography with global and USArray

509 Transportable Array data, Seismol. Res. Lett., 81, 689-693.

510 Calkins, J. A., G. A. Abers, G. Ekström, K. C. Creager, and S. Rondenary (2011),

511 Shallow structure of the Cascadia subduction zone beneath western Washington from

512 spectral ambient noise correlation, J. Geophys. Res., 116, B07302,

513 doi:10.1029/2010JB007657.

514 Calvert, A. J., M. A. Fisher, and SHIPS Working Group (2001), Imaging the Seattle fault 515 zone with high-resolution seismic tomography, Geophys. Res. Lett., 28, 2337-2340.

516 Chen, P., T. H. Jordan, and L. Zhao (2007), Full three-dimensional tomography: a

517 comparison between the scattering-integral and adjoint-wavefield methods, Geophys. $518 \quad$ J. Int., 170, 175-181.

519 Christensen, N. I., and W. D. Mooney (1995), Seismic velocity structure and composition 520 of the continental crust: A global view, J. Geophys. Res., 100, 9761-9788.

521 Conder, J. A., (2005), A case for hot slab surface temperatures in numerical viscous flow 522 models of subduction zones with an improved fault zone parameterization, Phys.

$523 \quad$ Earth Planet. Inter., 149, 155-164.

524 Conder, J. A., D. A. Wiens, and J. Morris (2002), On the decompression melting 525 structure at volcanic arcs and back-arc spreading centers, Geophys. Res. Lett., 29, 
doi:10.1029/2002GL015390.

527 Crosson, R. S., N. P. Symons, K. C. Creager, L. A. Preston, T. van Wagoner, T. M.

528 Brocher, M. Fisher, and the SHIPS Working Group (2002), Three-dimensional

529 structure of the Cascadia forearc region from SHIPS active experiment and

530 earthquake observations: tomographic inversion provides a high-resolution view into

531 the core of the Cascadia forearc complex, U.S. Geological Survey Open-File Report

$532 \quad$ 02-328 and Geological Survey of Canada Open File 4350, 33-34.

533 Currie, C. A., K. Wang, R. D. Hyndman, and J. He (2004), The thermal effects of steady-

534 state slab-driven mantle flow above a subducting plate: the Cascadia subduction zone

535 and backarc, Earth Planet. Sci. Lett., 223, doi:10.1016/j.eps1.2004.04.020.

536 Dahlen, F. A., and Y. Zhou (2006), Surface-wave group-delay and attenuation kernels,

537 Geophys. J. Int., 165, 545-554.

538 Dalton, C. A., G. Ekström, and A. M. Dziewoński (2008), The global attenuation

539 structure of the upper mantle, J. Geophys. Res., 113, B09303,

540 doi:10.1029/2007JB005429.

541 Dasgupta, R., A. Mallik, K. Tsuno, A. C. Withers, G. Hirth, and M. M. Hirschmann

542 (2013), Carbon-dioxide-rich silicate melt in the Earth's upper mantle, Nature, 493,

$543 \quad 211-216$

544 Delorey, A. A., and J. E. Vidale (2011), Basin shear-wave velocities beneath Seattle,

545 Washington, from noise-correlation Rayleigh waves, Bull. Seism. Soc. Am., 101,

$546 \quad 2162-2175$, doi:10.1785/0120100260.

547 Druken, K. A., M. D. Long, and C. Kincaid (2011), Patterns in seismic anisotropy driven

548 by rollback subduction beneath the High Lava Plains, Geophys. Res. Lett., 38, 
550 Egbert, G. D. (2012), Three-dimensional inversion of EarthScope magnetotelluric data:

551 crustal and mantle conductivity beneath the NW USA. IRIS Webinars,

552 http://www.iris.edu/hq/webinar (November 27, 2012).

553 Elkins Tanton, L. T., T. L. Grove, and J. Donnelly-Nolan (2001), Hot, shallow mantle

554 melting under the Cascades volcanic arc, Geology, 29, 631-634.

555 Fichtner, A., and J. Trampert (2011), Resolution analysis in full waveform inversion,

556 Geophys. J. Int., 187, 1604-1624.

557 Gao, H., and Y. Shen (2012), Validation of Shear-wave velocity models of the Pacific

$558 \quad$ Northwest, Bull. Seismol. Soc. Am., 102(6), 2611-2621.

559 Gao, H., E. D. Humphreys, H. Yao, and R. D. van der Hilst (2011), Crust and lithosphere

560 structure of the Northwestern U.S. with ambient noise tomography: Terrane accretion

561 and Cascade arc development, Earth Planet. Sci. Lett., 304,

562 doi:10.1016/j.epsl.2011.01.033.

563 Graindorge, D., G. Spence, P. Charvis, J. Y. Collot, R. Hyndman, and A. M. Tréhu

564 (2003), Crustal structure beneath the Strait of Juan de Fuca and southern Vancouver

565 Island from seismic and gravity analyses, J. Geophys. Res., 108 (B10), 2484,

566 doi:10.1029/2002JB001823.

567 Hall, P. S., and C. Kincaid (2001), Diapiric flow at subduction zones: A recipe for rapid

$568 \quad$ transport, Science, 292, 2472-2475.

569 Hasenclever, J., J. P. Morgan, M. Hort, and L. H. Rüpke (2011), 2D and 3D numerical

570 models on compositionally buoyant diapirs in the mantle wedge, Earth Planet. Sci.

$571 \quad$ Lett., 311, 53-68, doi:10.1016/j.eps1.2011.08.043. 
572 Honda, S. (2011), Planform of small-scale convection under the island arc, Geochem.

573 Geophys. Geosyst., 12, Q11005.

574 Honda, S., and T. Yoshida (2005), Application of the model of small-scale convection

575 under the island arc to the NE Honshu subduction zone, Geochem. Geophys.

576 Geosyst., 6, Q01002, doi:10.1029/2004GC000785.

577 Hopper, E., H. A. Ford, K. M. Fischer, V. Lekic, and M. J. Fouch (2013), The

578 lithosphere-asthenosphere boundary and the tectonic and magmatic history of the 579 northwestern United States, in review.

580 Hung, S.-H., Y. Shen, and L.-Y. Chiao (2004), Imaging seismic velocity structure

581 beneath the Iceland hotspot - A finite-frequency approach, J. Geophys. Res., 109, $582 \quad$ B08305, doi:10.1029/2003JB002889.

583 Ingebritsen, S. E., and R. H. Mariner (2010), Hydrothermal heat discharge in the Cascade

584 Range, northwestern United States, J. Volcanol. Geotherm. Res., 196, 208-218,

585 doi:10.1016/j.jvolgeores.2010.07.023.

586 Isse, T. et al. (2009), Seismic structure of the upper mantle beneath the Philippine Sea

587 from seafloor and land observation: Implications for mantle convection and magma

588 genesis in the Izu-Bonin-Mariana subduction zone, Earth Planet. Sci. Lett., 278, 107-

$589 \quad 117$.

590 Jackson, I., and U. H. Faul (2010), Grainsize-sensitive viscoelastic relaxation in olivine:

591 Towards a robust laboratory-based model for seismological application, Phys. Earth

592 Planet. Inter., 183, 151-163.

593 James, D. E., M. J. Fouch, R. W. Carlson, and J. B. Roth (2011), Slab fragmentation,

594 edge flow and the origin of the Yellowstone hotspot track, Earth Planet. Sci. Lett., 
596 Kelley, K. A., T. Plank, T. L. Grove, E. M. Stolper, S. Newman, and E. Hauri (2006),

597 Mantle melting as a function of water content beneath back-arc basins, J. Geophys.

$598 \quad$ Res., 111, B09208, doi:10.1029/2005JB003732.

599 Kennett, B. L. N., E. R. Engdahl, and R. Buland (1995), Constraints on seismic velocities 600 in the Earth from travel times, Geophys. J. Int., 122, 108-124.

601 Kincaid, C., K. A. Dreken, R. W. Griffiths, and D. R. Stegman (2013), Bifurcation of the 602 Yellowstone plume driven by subduction-induced mantle flow, Nature Geoscience, 6, 603 doi:10.1038/NGEO1774.

604 Kumar, P., R. Kind, X. Yuan, and J. Mechie (2012), USArray receiver function images of 605 the lithosphere-asthenosphere boundary, Seis. Res. Lett., 83, 606 doi:10.1785/gssrl.83.3.486.

607 Lawrence, J. F., and G. A. Prieto (2011), Attenuation tomography of the western United 608 States from ambient seismic noise, J. Geophys. Res., 116, B06302, 609 doi:10.1029/2010JB007836.

610 Lee, J. M., and R. S. Crosson (1990), Tomographic imaging of local earthquake delay 611 times for three-dimensional velocity variation in western Washington, J. Geophys. 612 Res., 95, 4763-4776.

613 Lévêque, J. J., L. Rivera, and G. Wittlinger (1993), On the use of the checkerboard test to 614 assess the resolution of tomographic inversions, Geophys. J. Int., 115, 313-318.

615 Lowry, A. R., and M. Pérez-Gussinyé (2011), The role of crustal quartz in controlling 616 Cordilleran deformation, Nature, 471, 353-357, doi:10.1038/nature09912. 
617 McCrory, P. A., J. L. Blair, D. H. Oppenheimer, and S. R. Walter (2004), Depth to the 618 Juan de Fuca slab beneath the Cascadia subduction margin: A 3-D model for sorting 619 earthquakes, U.S. Geol. Surv. Data Ser. DS-91.

620 McCrory, P. A., J. L. Blair, F. Waldhauser, and D. H. Oppenheimer (2012), Juan de Fuca 621 slab geometry and its relation to Wadati-Benioff zone seismicity, J. Geophys. Res., $622 \quad$ 117, B09306, doi:10.1029/2012JB009407.

623 Morishige, M., and S. Honda (2011), Three-dimensional structure of P-wave anisotropy 624 in the presence of small-scale convection in the mantle wedge, Geochem. Geophys. 625 Geosyst., 12, Q12010, doi:10.1029/2011GC003866.

626 Moschetti, M. P., M. H. Ritzwoller, F.-C Lin, and Y. Yang (2010), Crustal shear wave 627 velocity structure of the western United States inferred from ambient seismic noise 628 and earthquake data, J. Geophys. Res., 115, B10306, doi:10.1029/2010JB007448.

629 Nishimura, C. E., and D. W. Forsyth (1989), The anisotropic structures of the upper 630 mantle in the Pacific, Geophys. J., 96, 203-229, doi:10.1111/j.1365$631 \quad$ 246X.1989.tb04446.x.

632 Obrebski, M., R. M. Allen, M. Xue, and S.-H. Hung (2010), Slab-plume interaction 633 beneath the Pacific Northwest, Geophys. Res. Lett., 37, L14305, 634 doi:10.1029/2010GL043489.

635 Obrebski, M., R. M. Allen, F. Pollitz, and S.-H. Hung (2011), Lithosphere-asthenosphere 636 interaction beneath the western United States from the joint inversion of body-wave 637 traveltimes and surface-wave phase velocities, Geophys. J. Int., 185, 1003-1021.

638 Parsons T., R. E. Wells, M. A. Fisher, E. Flueh, and ten Brink U. S. (1999), Three639 dimensional velocity structure of Siletzia and other accreted terranes in the Cascadia 
640 forearc of Washington, J. Geophy. Res., 104, 18,015-18,039, doi:

$641 \quad 10.1029 / 1999 J B 900106$.

642 Porritt, R. W., R. M. Allen, D. C. Boyarko, and M. R. Brudzinski (2011), Investigation of 643 Cascadia segmentation with ambient noise tomography, Earth Planet Sci. Lett., 309, $644 \quad$ 67-76, doi:10.1016/j.epsl.2011.06.026.

645 Ramachandran, K., S. E. Dosso, C. Zelt, G. D. Spence, R. D. Hyndman, and T. M.

646 Brocher (2004), Upper crustal structure of Southwestern British Columbia from the

6471998 Seismic Hazards Investigation in Puget Sound, J. Geophy. Res., 109, B9, 648 B09303, doi: 10.1029/2004JB003092.

649 Roth, J. B., M. J. Fouch, D. E. James, and R. W. Carlson (2008), Three-dimensional 650 seismic velocity structure of the northwestern United States, Geophys. Res. Lett., 35, $651 \quad$ L15304, doi:10.1029/2008GL034669.

652 Ruscitto, D. M., P. J. Wallace, E. R. Johnson, A. J. R. Kent, and I. N. Bindeman (2010), 653 Volatile contents of mafic magmas from cinder cones in the Central Oregon High 654 Cascades: implications for magma formation and mantle conditions in a hot arc, 655 Earth Planet. Sci. Lett., 298, 153-161, doi:10.1016/j.eps1.2010.07.037.

656 Sabra, K. G., P. Roux, and W. A. Kuperman (2005), Emergence rate of the time-domain 657 Green's function from the ambient noise cross-correlation function, J. Acoust. Soc. $658 \quad$ Am., 118, 3524-3531.

659 Schmandt, B., and E. Humphreys (2010), Complex subduction and small-scale 660 convection revealed by body-wave tomography of the western United States upper 661 mantle, Earth Planet. Sci. Lett., 297, 435-445, doi:10.1016/j.epsl.2010.06.047.

662 Schmandt, B., and E. Humphreys (2011), Seismically imaged relict slab from the $55 \mathrm{Ma}$ 
663 Siletzia accretion to the northwest United States, Geology, 39, 175-178.

664 Schmidt, M. E., A. L. Grunder, and M. C. Rowe (2008), Segmentation of the Cascade

665 Arc as indicated by $\mathrm{Sr}$ and $\mathrm{Nd}$ isotopic variation among diverse primitive basalts.

666 Earth Planet. Sci. Lett., 266, 166-181.

667 Shapiro, N. M., and M. H. Ritzwoller (2002), Monte-Carlo inversion for a global shear

668 velocity model of the crust and upper mantle, Geophys. J. Int., 151, 88-105.

669 Shen W., M. H. Ritzwoller, and V. Schulte-Pelkum (2013), A 3-D model of the crust and

670 uppermost mantle beneath the Central and Western US by joint inversion of receiver

671 functions and surface wave dispersion, J. Geophys. Res. Solid Earth, 118,

672 doi:10.1029/2012JB009602.

673 Shen, Y., Y. Ren, H. Gao, and B. Savage (2012), An improved method to extract very

674 broadband empirical Green's functions from ambient seismic noise, Bull. Seism. Soc.

$675 \quad A m ., 102$ (4).

676 Shen, Y., and W. Zhang (2010), Full-wave ambient noise tomography of the northern

677 Cascadia, SSA meeting (abstract), Seismological Research Letters, 81, 300.

678 Sherrod, D. R., and J. G. Smith (1990), Quaternary extrusion rates of the Cascade Range,

679 Northwestern United States and Southern British Columbia, J. Geophys. Res., 95,

$680 \quad 19,465-19,474$

681 Sigloch, K. (2011), Mantle provinces under North America from multi-frequency P wave 682 tomography, Geochem. Geophys. Geosyst., 12, Q02W08, 683 doi:10.1029/2010GC003421.

684 Snieder, R. (2004), Extracting the Green's function from the correlation of coda waves: a 685 derivation based on stationary phase, Phys. Rev. E., 69, 046610. 
686 Sparks, D. W., and E. M. Parmentier (1991), Melt extraction from the mantle beneath 687 spreading centers, Earth Planet. Sci. Lett., 105, 368-377.

688 Symons, N. P., and R. S. Crosson (1997), Seismic velocity structure of the Puget Sound 689 region from 3-D non-linear tomography, Geophys. Res. Lett., 24, 2593-2596.

690 Tamura, Y., Y. Tatsumi, D. Zhao, Y. Kido, and H. Shukuno (2002), Hot fingers in the 691 mantle wedge: New insights into magma genesis in subduction zones, Earth Planet. 692 Sci. Lett., 197, 105-116.

693 Till, C. B., T. L. Grove, R. W. Carlson, J. M. Donnelly-Nolan, M. J. Fouch, L. S.

694 Wagner, and W. K. Hart (2013), Depths and temperatures of $<10.5 \mathrm{Ma}$ mantle melting 695 and the lithosphere-asthenosphere boundary below southern Oregon and northern 696 California, Geochem. Geophys. Geosyst., 14, 864-879, doi:10.1002/ggge.20070. 697 Tréhu, A. M., I. Asudeh, T. M. Brocher, J. H. Luetgert, W. D. Mooney, J. L. Nabelek, 698 and Y. Nakamura (1994), Crustal architecture of the Cascadia forearc, Science, 266, $699 \quad$ 237-243, doi:10.1126/science.266.5183.237.

700 Tréhu, A. M., T. M. Brocher, K. C. Creager, M. A. Fisher, L. Preston, and G. D. Spence 701 (2002), Geometry of the subducting Juan de Fuca Plate: New constraints from 702 SHIPS98, in The Cascadia Subduction Zone and Related Subduction Systems:

703 Seismic Structure, Intraslab Earthquakes and Processes, and Earthquake Hazards, 704 edited by S. Kirby, K. Wang, and S. Dunlop, U.S. Geol. Surv. Open File Rep., 02328, 705 25-32. (Available at http://geopubs.wr.usgs.gov/open-file/of02-328/).

706 Tromp, J., Y. Luo, S. Hanasoge, and D. Peter (2010), Noise cross-correlation sensitivity 707 kernels, Geophys. J. Int., doi:10.1111/j.1365-246X.2010.04721.x. 
708 Tsai, V. C., and M. P. Moschetti (2010), An explicit relationship between time-domain

709 noise correlation and spatial autocorrelation (SPAC) results, Geophys. J. Int., 182(1),

710 454-460, doi:10.1111/j.1365-246X.2010.04633.x.

711 Uchiyama, Y., and J. C. McWilliams (2008), Infragravity waves in the deep ocean:

712 Generation, propagation, and seismic hum excitation, J. Geophys. Res., 113, C07029,

713 doi:10.1029/2007JC004562.

714 van Keken, P. E., (2003), The structure and dynamics of the mantle wedge, Earth Planet.

$715 \quad$ Sci. Lett., 215, 323-338.

716 van Keken, P. E., B. R. Hacker, E. M. Syracuse, and G. A. Abers (2011), Subduction

717 factory: 4. Depth-dependent flux of $\mathrm{H} 2 \mathrm{O}$ from subducting slabs worldwide, $J$.

718 Geophys. Res., 116, B01401, doi:10.1029/2010JB007922.

719 van Wagoner, T. M., R. S. Crosson, K. C. Creager, G. F. Medema, L. A. Preston, N. P.

720 Symons, and T. M. Brocher (2002), Crustal structure and relocated earthquakes in the

721 Puget Lowland, Washington from high resolution seismic tomography, J. Geophys.

$722 \quad$ Res., 107, B12, 10.10129/2001JB000710.

723 Wagner, L. S., M. J. Fouch, D. James, S. Hanson-Hedgecock (2012), Crust and upper

724 mantle structure beneath the Pacific Northwest from joint inversions of ambient noise

725 and earthquake data, Geochem., Geophys., Geosys., 13, doi:10.1029/2012GC04353.

726 Wang, K., T. Plank, J. D. Walker, and E. I. Smith (2002), A mantle melting profile across

727 the Basin and Range, SW USA, J. Geophys. Res., 107, doi:10.1029/2001JB000209.

728 Wapenaar, K. (2004), Retrieving the elastodynamic Green's function of an arbitrary

729 inhomogeneous medium by cross correlation, Phys. Rev. Lett., 93, 254301. 
730 Wapenaar, K., and J. Fokkema (2006), Green's function representations for seismic 731 interferometry, Geophysics, 71, S133-S146.

732 Wiens, D. A., K. A. Kelley, and T. Plank (2006), Mantle temperature variations beneath 733 back-arc spreading centers inferred from seismology, petrology, and bathymetry,

$734 \quad$ Earth Planet. Sci. Lett., 248, 30-42, doi:10.1016/j.eps1.2006.04.011.

735 Wiens, D. A., J. A. Conder, and U. H. Faul (2008), The seismic structure and dynamics

736 of the mantle wedge, Annu. Rev. Earth Planet. Sci., 36, 421-455,

737 doi:10.1146/annurev.earth.33.092203.122633.

738 Wiens, D. A., S. S. Wei, H. N. Relyea, M. Barklage, S. Pozgay, and J. A. Conder (2012),

739 Imaging mantle melting beneath island arcs and backarc spreading centers, Eos

740 Trans. AGU, V21C-03.

741 Yang, Y., and M. H. Ritzwoller (2008), Characteristics of ambient seismic noise as a

742 source for surface wave tomography, Geochem. Geophys. Geosys., 9, Q02008, 743 doi:10.1029/2007GC001814.

744 Yang, Y., M. H. Ritzwoller, F.-C. Lin, M. P. Moschetti, and N. M. Shapiro (2008),

745 Structure of the crust and uppermost mantle beneath the western United States

746 revealed by ambient noise and earthquake tomography, J. Geophys. Res., 113,

$747 \quad$ B12310, doi:10.1029/2008JB005833.

748 Yuan, H., and B. Romanowicz (2010), Lithospheric layering in the North American

$749 \quad$ craton, Nature, 466, doi:10.1038/nature09332.

750 Zhang, Z., Y. Shen, and L. Zhao (2007), Finite-frequency sensitivity kernels for head

$751 \quad$ waves, Geophys. J. Int., 171, 847-856.

752 Zhang, W., Y. Shen, and L. Zhao (2012), Three-dimensional anisotropic seismic wave 
753 modeling in spherical coordinate by a collocated-grid finite difference method,

754 Geophys. J. Int., 188, 1359-1381, doi:10.1111/j.365-246X.2011.05331.x.

755 Zhao, D., Y. Xu, D. A. Wiens, L. Dorman, J. Hildebrand, and S. Webb (1997), Depth

756 extent of the Lau back-arc spreading center and its relation to subduction processes,

$757 \quad$ Science, 278, 254-257.

758 Zhao, L., T. H. Jordan, K. B. Olsen, and P. Chen (2005), Fréchet kernels for imaging

759 regional earth structure based on three-dimensional reference models, Bull. Seism.

760 Soc. Am., 95, 2066-2080.

761 Zhao, D. P., K. Wang, G. C. Rogers, and S. M. Peacock (2001), Tomographic image of

762 low P velocity anomalies above slab in northern Cascadia subduction zone, Earth,

$763 \quad$ Planets and Space, 53, 285-293.

764 Zhou, Y. (2009), Surface-wave sensitivity to 3-D anelasticity, Geophys. J. Int., 178,

$765 \quad 1403-1410$.

766

767

768 Figure Captions

769 Figure 1. Schematic illustration of possible melt generation and migration processes at

770 general subduction zones, which may depend on the slab age, sediment thickness,

771 subduction rate, and other factors. Thin lines with open arrows indicate melt paths, while

772 those with solid arrows represent mantle flow lines. VF stands for the volcanic front.

773

774 Figure 2. Segmentation of the Cascade arc volcanoes (red triangles), defined by

775 geochemical signatures (Schmidt et al., 2008), and distribution of seismic stations used in 
776 this study (white dots). The depth contours of the Juan de Fuca plate interface at 20-100

$777 \mathrm{~km}$ are from the model of McCrory et al. (2004). The time-progressive Newberry (NB)

778 and Yellowstone (YS) rhyolite eruptive progression across Snake River Plain (SRP) and

779 High Lava Plains (HLP) are shown as thin brown lines (in Ma). CB stands for the

780 Columbia basin.

781

782 Figure 3. Example of Empirical Green's Functions. (a) The lines connect the receivers

783 (blue triangles) to the "virtual source" (red dot). (b-c) EGFs from the "source" to all the

784 other stations derived from ambient noise cross-correlation of vertical-to-vertical

785 components are plotted by the inter-station distance, filtered at 100-200 s and 10-25 s,

786 respectively.

787

788 Figure 4. Observed EGFs vs. synthetics, filtered at periods of 10-25 s. (a) The lines

789 connect the "source" (red triangle) to the receivers (blue triangles). (b-c) Comparison of

790 observed waveforms (black lines) and synthetics (red lines), sorted by the distance

791 between the "source" and each receiver. Synthetic waveforms are generated from the

792 initial reference model (b) and our full-wave tomographic model (c), respectively.

793

794 Figure 5. Comparison of phase delay time between observed and synthetic waveforms

795 from the initial reference model (black) and our full-wave ambient noise tomography

796 (red). (a-b) The phase delay time versus inter-station distance at periods of 50-100 s and

$79725-50 \mathrm{~s}$, respectively. (c-d) The histogram of phase delay time at corresponding period

798 ranges. It shows that the improvement in fitting the data with our updated model. 
800 Figure 6. Shear-wave velocity structure (in $\mathrm{km} / \mathrm{s}$ ) at multiple depths. All the panels share 801 the same velocity scale, as denoted by the color bar. Other symbols are the same as in 802 Figure 2.

804 Figure 7. Segmented low-velocity anomalies along the Cascade back-arc. (a) Horizontal 805 slice at depth of $94 \mathrm{~km}$ (Vs in $\mathrm{km} / \mathrm{s}$ ). The black dashed lines outline the amplitude of 806 largest negative Sp phase from receiver functions in the back-arc (Hopper et al., 2013). 807 The magenta lines mark the profile locations in (b), (c), (d) and (e), respectively. The 808 three white dots mark the point locations in Figure 8. All the panels share the same color 809 bar. (b-d) W-E profiles across the back-arc anomalies. The y-axis has the approximate 810 same length scale as the x-axis. The triangles mark the volcano centers. The Juan de Fuca 811 plate interface at depths of $20-100 \mathrm{~km}$ from the model of McCrory et al. (2004) is 812 projected. At greater depth, the plate interface is poorly defined. (e) S-N profile along the 813 back-arc low-velocity anomalies, which spatially correlate with the three volcano clusters 814 as in Figure 1. The length scale of y-axis is exaggerated two times of the $x$-axis.

816 Figure 8. Point velocity versus depth. (a) Comparison of velocities for points above the 817 back-arc anomalies (blue) with the velocities of the Lau Basin (red) and the 0-4 Ma 818 Pacific upper mantle (black) (based on Wiens et al. (2008)), and the calculated velocity 819 for the Cascade geotherm (gray, the same as the black line in (b)). (b) Comparison of the 820 observed and calculated shear-wave velocities. The blue lines are the observed back-arc 821 velocities, the same as in (a). The other four lines are calculated (with the code from 
822 Jackson and Faul (2010)) for the four geothermal profiles in (c) based on Figure 4 of

823 Currie et al. (2004). In the legend of (c), the first number indicates the surface heat flow

824 (in $\mathrm{mW} / \mathrm{m}^{2}$ ) and the second one is the potential temperature of the mantle (in ${ }^{\circ} \mathrm{C}$ ). The

825 difference between the calculated velocity and the observed is suggestive of the presence

826 of partial melt.

827

828 Figure 9. Resolution test for the low-velocity anomalies along the back-arc imaged in this

829 study. (Upper panels) Input model is our preferred tomographic model; (Lower panels)

830 Recovered velocities at the corresponding depths. Note that the amplitude of the velocity

831 perturbation is not fully recovered partly because of the damping and smoothing factors

832 used in the inversion.

833

834 Figure 10. Vertical resolution test along three W-E profiles that cross the back-arc low 835 velocity anomalies. (Upper panels) Input model is our preferred tomographic model, 836 same as in Figure 9. The three profiles correspond to the cross-sections in Figures 7b-7d, 837 respectively. The velocity perturbation varies within a range of $\pm 10 \%$. (Lower panels) 838 The recovered velocity models along the corresponding vertical profiles. 